\title{
Does the Use of Piercing Can Harm Health and Lead to Obesity?
}

\section{Huang Wei Ling*}

Infectious Diseases, General Practice, Nutrition, Acupuncture and Pain Management,

Medical Acupuncture and Pain Management Clinic, Franca, São Paulo, Brazil

*Corresponding Author: Huang Wei Ling, Infectious Diseases, General Practice, Nutrition, Acupuncture and Pain Management, Medical Acupuncture and Pain

Management Clinic, Franca, São Paulo, Brazil.

Today the author wants to talk about one thing she never saw in any scientific publications about the possible harmful effects that the use of piercings could cause in the human body. What she will say in this article came from the observation from her daily clinical practice in Brazil.

There is some article Yin the literature, one of them written by Holbrook in an article entitled Body piercing: complications and prevention of health risks, where the author is saying about some complications related to the physical aspects of when putting piercing inside the body. This complication could be: local or systemic infections (viral hepatitis), bleeding, toxic shock syndromes, and distant infections such as endocarditis and brain abscesses have been reported. Other side effects that the use of piercing could induce is nerve damage, keloid formation and scarring [1].

The author has 6 medical specialties and she had the opportunity to learn both types of medicine (Western and Eastern) and therefore she has the knowledge to evaluate and assess the patient in different ways of reasoning by Western medicine and in a deeper way, where Chinese medicine can see, in the energy point of view [2].

In this article, the author will give emphasis to the other aspect that Western medicine do not understand well until today that is the energy aspect in the human being. This aspect is well demonstrated in the book Tao of Physics written by Capra (1975) where he is saying the different views between one medicine and another. One (Western) considered scientific by the modern medicine and the other (Eastern) considered more mystic and not considered yet scientific [3].
Received: July 31, 2021

Published: August 12, 2021

(C) All rights are reserved by Huang Wei Ling.
But in the point of view of the author, the two medicines is saying about the same subject, but in different perspectives, one is looking at the leaf level, and the other is looking at the root level, demonstrated in many articles published by the author [3-7].

All this differences became bigger when Flexner implanted a report in 1913, when all medical schools in the three main continents should teach their medical students according to the new model of medicine, with Rockefeller foundation and Carnegie Foundation behind him with financial intention. But he was not a doctor, he was just a teacher and he made the changes in all medical schools from the point of view of a teacher and not knowing exactly how it would be like actually how a human being is formed from the material point of view and from the energy point of view $[8,9]$.

According to traditional Chinese medicine, all diseases is caused by the internal energy imbalance between Yin, Yang, Qi and Blood [4-7].

In the author clinical practice, she usually measures the patient's internal energy of the five massive organs (Liver, Heart, Spleen, Lung and Kidney) to evaluate how is the energy of each organ. According to the article written by Christopher (2018) entitled The Geometry of Emotions: Using Chakra Acupuncture and 5-Phase Theory to Describe Personality Archetypes for Clinical Use, he is doing a correspondence between the chakras' energy centers (studied by Ayurveda in India culture) and the five elements in traditional Chinese medicine. So, measuring the chakras' energy centers, she will be measuring the energy of the five massive organs that are responsible for the production of Yin, Yang, Qi and Blood, to maintain health $[4,5,10]$. 
In the article written by the author (2019) entitled Can Biomaterial Surgical Implants Influence the Body's Health, the author is demonstrating through this article, the possible harm effects caused by this metallic implants, in the energy point of view, not seeing by the naked eyes, leading to diverse manifestations such as depression symptoms (presented by both patients in two case reports) [11].

We can see patients using piercing in any site of the body such as in the ears (each part of the ear is affecting one part of the body that this region is correspondent) because the ear represents an inverted fetus and the part the represents the head is in the lobe of the ear and the part that represents the lower limbs is represented by the top of the ear, They can also be inserted in the tongue (and the tongue also represents all parts of the body) and depending on the part that the tongue is receiving piercing the organ that it represents could be affected negatively, taking out the energy, as the author could demonstrate this effect in this article, doing 0-ring test on her patients, attesting in this form, that the object can harm the internal energy $[4,5,11]$.

If the piercing is inserted in the nipples, can affect the energy of the Stomach (due to the fact that stomach meridian pass in this site) [12].

When the piercing is inserted in the belly button, it can cause many side effects due to the fact that this point is representing the Kidney, important for the production of Yin and Yang energy. Kidney energy is important to maintain rejuvenated, to keep the teeth, bones, earing process and also, for the reproduction and sexuality $[7,13]$.

Depending on where it was inserted, it could induce some problems in the organ that this area represents. For example, one patient put a piercing in the area that corresponds her wrists and sometime after (approximately two years later) she started to have pain in the wrists. Depending on the type of material that the patient is using to pierce the body, the reaction of the body could be different. According to the article, Can Biomaterial Surgical Implants Influence the Body's Health, metallic implants can reduce the vital energy of the patients weakening their body [11].

In this article published by the author (2019) shown above, the use of metallic implants can cause health problems like in the first case report, that she showed that the patient placed metallic in- struments post tibia fracture that he needs to insert after a motorcycle accident. And the second case was the placement of titanium implants in the tooth. Both had problems with the surgery in which the first type had a very serious depression symptom that did not got better after the use of anti-depressant medication. He got better only after he removed the implant from his tibia two hours' latter [11].

The second patience also had depression symptoms and was not improving her depression, even with the use of medications [11].

Both patients did chakras' energy measurement and both were in the lowest level of energy, with the exception of the seventh chakra, that was in normal rate, in eight [11].

The problem that the medicine is facing nowadays, is related to this not integration of both views (Western and Eastern) and many diseases begins in the energy level, but Western medicine only do the diagnosis only in very late phase, when there are alterations in the laboratory exams (phase four and five of the formation from health to disease) $[4,5]$.

The lack of understanding of the fact that the human being is made of the transformation of matter and energy in our body, our universe, the functioning of the human being, makes Western medicine currently unaware of the harm caused by the piercing, in the energy level [3].

To understand this whole process, we need to understand that everything that exists in the universe, including the human being, is formed by energy. The chair, the paper, the pen, everything the author is using to write this article are formed of energy. Even the author thoughts, to reason to write these few lines, are made by energy, to complete this article [3].

The actual model that medicine is doing all her reasoning, is based only in matter, not in energy (in the deepest level of transformation of one in another). And for this reason, they cannot understand yet and are ignoring the resistance of the energy part, that is the same thing, viewed by different perspective, made medicine not understanding what could the cause that can lead to the formation of many disease, when the patient is putting piercing or any metallic implant inside the body $[3,11]$. 
As said by the author in the beginning of this article, all diseases came from energy imbalances. The reduction of energy caused by the use of piercing could lead to many disease in the phase four and five, demonstrated in many articles, such as diabetes, hypertension, myocardial infarction, tremors, cancer and many other chronic diseases, that depends on the health energy to maintain the individual without any diseases [4-6,14-16].

With the implantation of the $5 \mathrm{G}$ technology of cell phones, leads to changes in the energy of the human body and this data was published in the article written by the author entitled Chakras' Energy Deficiencies and Propensity to SARS-CoV-2 Infection. In this study, the author showed that $90 \%$ of patients her 1000 patients that she attended from 2015 to 2020, have no energy in the chakras' energy centers. Only $70 \%$ had energy in the seventh chakra (spiritual chakra) but $20 \%$ also do not have any energy inside the seventh chakra [17].

According to another article written by the author (2021) entitled Are We Vaccinating Immunocompetent or Immunocompromised People for COVID-19?, the author is saying that, due to the fact that the cause of this energy deficiency is due to the electromagnetic waves, that is affecting the whole world, the author is saying that this data that she had in Brazil could be happening in the whole world, and for this reason, the majority of people nowadays are considered immunocompromised and nor immunocompetent, because in traditional Chinese medicine, energy means immune system and the lack of energy is leading to poor immune system in all age groups, as demonstrated by the author in this article [18].

The use of piercing in a population currently already compromised energy leads to an even greater energy deficiency leading this population to an increased risk of chronic diseases, as the author mentioned before [4-7,14-16].

Regarding the induction of obesity, that the author is questioning if this is possible, the author observed that, in her daily practice, patients who reported having the piercing performed a few years ago had reports to have a very large weight gain after having it.

This evolution could due to the fact that, as the author had already said, the current population in the whole world is very weak in energy and when this same person decides to put piercing in the ear or other parts of the body, the energy of this person could reduce even more. And to maintain the body's thin, it is necessary energy and with no energy, the propensity to increase weight will occur. The treatment of this condition includes the advice of the patient to try to remove the piercings and begin to treat the condition of lack of energy in the five massive organs that is very common nowadays [11].
The second step in this treatment includes the Chinese dietary counseling. Why the author is saying that is needs to be Chinese? Because this type of dietary aspects is based on the energy of each food treating the energy imbalances presented by each patient. In traditional Chinese medicine, they do not give raw salad to all person that want to lose weight, because eat salad that is considered raw food, have Cold energy, that will cause Spleen energy deficiency, leading to retention of Phlegm inside the body, increasing weight instead of reducing weight. Depends on the energy deficiency presented by each patient, the doctor will advise accordingly [19].

However, some patients find resistance in taking out the piercing, even when receiving guidance that they can cause harm to the development of other diseases in the future.

All the changes in the dietary aspect of this patients are described in many publications of the author, one of this article written by her (2020) entitled Why Are Diabetic Patients Still Having Hyperglycemia despite Diet Regulation, Antiglycemic Medication and Insulin? [5].

Therefore, changing the curriculum of medical schools in the world should be implemented because the deeper medical knowledge of energy changes is very important nowadays because the lack of knowledge of this aspects in the human being is bringing many other delay in prevention of disease formation, only doing treatments after the onset of disease formation. The other aspect very important to say is that the population that we are attending nowadays are very different from the patient before 2015 . Nowadays, we are in a new era of the history of medicine, that if we prescribe medications recommended for the patients to treat variety of diseases, this medication (highly concentrated medications) will harm even more this energy that is already low, leading to the formation of other diseases in the future or even causing death, according to Arndt Shultz Law. This situation we are facing nowadays, in this pandemic, because the patients that is sick, is receiving medications to treat their condition that is worsening the vital energy and the use of drugs that was considered scientific in the past, is causing harm in the vital energy of this patients leading to complications or even death, as showed in the article written by the author entitled Is the Medication used in Intubation of Patients with Covid-19 Affecting the Outcome of the Patient's Treatment? $[17,20,21]$.

And medications considered non-scientific such as the homeopathies, are now the medications of choice for the type of population that we are having nowadays, as demonstrated in the article Is the Population in the World the Same as in the Past? [22]. 
So, though this article, the author is showing that the insertion of piercing in the body can lead to many problems in the present and also, in the future, generated by the energy deficiencies caused by the implantation of metal inside the body [11].

\section{Bibliography}

1. Holbrook J., et al. "Body piercing: complications and prevention of health risks". American Journal of Clinical Dermatology 13.1 (2012): 1-17.

2. Ling HW. "What have behind in all kinds of infections that we need to know?" Journal of Investigative Oncology 1.1 (2021): 18-21.

3. Capra Fritjof. The Tao Of Physics : an Exploration of the Parallels between Modern Physics and Eastern Mysticism. Berkeley : [New York]. :Shambhala ; distributed in the U.S. by Random House (1975).

4. Huang WL. "Why do Patients Still Catch Hospital Infections Despite the Practice of Infection Prevention and Control Programs?" Acta Scientific Microbiology 1.4 (2018): 34-43.

5. Huang WL. "Why Are Diabetic Patients Still Having Hyperglycemia despite Diet Regulation, Antiglycemic Medication and Insulin?" International Journal of Diabetes and Metabolic Disorder 4.2 (2019): 1-14.

6. Huang WL. "Energy Alterations as the Underlying Cause of Primary Hypertension?" Journal of Nephrology 4.2 (2019): 33-44.

7. Huang WL. "Why patients with knee pain still have symptoms despite the use of anti-inflammatory medications". Journal of Clinical Anesthesiology: Open Access 2.2 (2020): 21-7.

8. Stahnisch F and Verhoef M. "The flexner report of 1910 and its impact on complementary and alternative medicine and psychiatry in north america in the 20th century". EvidenceBased Complementary and Alternative Medicine 2012 (2012): 647896.

9. Duffy T. "The Flexner Report - 100 Years Later”. Yale Journal of Biology and Medicine 84.3 (2011): 269-276.

10. Chase CR. "The Geometry of Emotions: Using Chakra Acupuncture and 5-Phase Theory to Describe Personality Archetypes for Clinical Use". Medical Acupuncture 30 (2018): 167-178.

11. Huang WL. "Can Biomaterial Surgical Implants Influence the Body' s Health". Acta Scientific Medical Sciences 3.9 (2019): 6271.

12. Clark Manning Louis Vanrenen. Bioenergetic Medicines East and West: Acupuncture and Homeopathy Paperback - February 9 (1993).
13. Huang WL. 'Energies Alterations and Chakras' Energies Deficiencies as the Main Cause of Rhinitis". Journal of Immunology and Immunotherapy 4 (2021): 009.

14. Huang WL. "The Importance of Correcting Energy Imbalances in the Prevention and Treatment of Câncer". Advances in Cancer Research and Clinical Imaging 3.1 (2020): 1-10.

15. Huang WL. "The Importance of Correcting Energy Imbalances in the Prevention and Treatment of Myocardial Infarction". Acta Scientific Medical Sciences 4.6 (2020): 20-27.

16. Huang WL. "Energies Alterations and Chakras Energies Deficiencies as Underlying Cause of Essential Tremors". Clinical Research in Neurologyis 3.2 (2020): 1-9.

17. Huang Wei Ling. "Energy Alterations and Chakras' Energy Deficiencies and Propensity to SARS-CoV-2 Infection". Acta Scientific Microbiology 4.4 (2021): 167-196.

18. Huang WL. "Are We Vaccinating Immunocompetent or Immunocompromised People for COVID 19?" Journal of Vaccines Research and Vaccination 7 (2021): 018.

19. PERINI Mauro. Chinese Diet Therapy. 2nd edition. LIVRARIA E EDITORA ANDREOLI (2020).

20. Huang Wei Ling. "Is the Medication used in Intubation of Patients with Covid-19 Affecting the Outcome of the Patient's Treatment?". Archives of Anesthesiology 4.1 (2021): 01-03

21. LEESER 0. "Support of homeopathy by the Arndt-Schulz law". National Center for Biotechnology Information. 1953/ Jul 31 (1953).

22. Huang Wei Ling. "Is the Population in the World the Same as in the Past?". Acta Scientific Clinical Case Reports 2.6 (2021).

\section{Volume 4 Issue 9 September2021}

(C) All rights are reserved by Huang Wei Ling. 